\title{
Helicobacter Pylori Treatment Eradication in Egypt: Standard Clarithromycin-based Triple versus Quadruple Regimen Therapy
}

\author{
Samir A. Afifi ${ }^{1}$, Neveen G. Elantouny ${ }^{1}$, Rehab H. El-sokkary ${ }^{2}$, Elsayed S. Abdelbaser ${ }^{3}$ \\ ${ }^{1)}$ Departments of Internal Medicine, ${ }^{(2)}$ Microbiology and Immunology, ${ }^{(3)}$ Tropical Medicine, Faculty of medicine, \\ Zagazig University, Zagazig, Egypt.
}

Corresponding Author Samir Abdel-Azim Morsy Afifi

\section{Mobile: \\ $+201211712820$ \\ E mail: \\ drsamir_2007@yahoo. com}

Key words: Helicobacter pylori, Stool antigen test, Clarithromycin-based triple therapy, Quadruple therapy
Background and study aim: Absence of adequate treatment for Helicobacter pylori (H. pylori) infection leads to prolonged life time colonization which is responsible for complications. Antibiotics resistance is the main cause of eradication failure in H. pylori infection, thus our study aimed to evaluate the efficiency and tolerability of standard triple therapy vs. quadruple regimen therapy in $\mathrm{H}$. pylori eradication in Egypt.

Subjects and Methods: Our study enrolled 140 patients (65 males,75 females) who attending to Gastroenterology clinic in Internal medicine \& Tropical medicine departments, Zagazig University Hospitals from (June 2018 - June 2019), aged from 20 - 60 years, complained of recurrent non-specific dyspepsia and epigastric pain \& proved to be positive for H. pylori stool antigen test. The patients distributed into two groups: group (1), 70

\section{INTRODUCTION}

$\mathrm{H}$. pylori is a gram negative bacilli in which infection is obtained during early adulthood, and transmitted to relatives but with lack of treatment early, it will build up prolonged life time colonization that is responsible for varieties of gastrointestinal disorders [1-2]. The severity of clinical symptoms related to $H$. pylori infection is associated to several virulence factors such as Vac A, Cag A, Ure A, Dup A, and etc. Vac A is a virulent gene that induce virulent factor leading to vaculation of the host cells [3]. The virulence factor causes induction of apoptosis through a certain specialized protein that causes depolarization of the cell membrane, disturbance in mitochondrial function, and suppression of $\mathrm{T}$ cell function [3]. patients given Clarithromycin triple therapy [Clarithromycin $500 \quad \mathrm{mg}+$ Amoxicillin 1gm + Pantoprazole $40 \mathrm{mg}$, each twice daily]. Group (2), 70 patients given quadruple therapy [Levofloxacin $500 \mathrm{mg}$ once daily + Nitazoxanide 500mg (twice daily)+ Doxycycline $100 \mathrm{mg}$ (twice daily)+ Pantoprazole $40 \mathrm{mg}$ (twice daily)] for 14 days.

Results: H. pylori eradication rate was statistically significant higher in patients who received quadruple therapy compared to those who received Clarithromycin-based triple therapy ( $85.7 \%$ vs. $\quad 67.1 \%$ \& $\mathrm{P}=0.001$ respectively).While, statistically insignificant regarding the treatment side effects in both groups ( $11.4 \%$ vs. 14.3 $\%, \mathrm{P}=0.33$ respectively).

Conclusion: Quadruple therapy is preferable to Clarithromycin-contained triple therapy in tolerability and eradication of $\mathrm{H}$. pylori in Egypt.

Cag A gene encodes a high immunogenic protein that has been used to identify $\mathrm{H}$. pylori. Cag A destructs the intracellular constituents of gastric epithelium via release of pro-inflammatory cytokines [4]. Attachment of $\mathrm{H}$. pylori to the gastric epithelium facilitates persistence of infection, initiates colonization, release of virulence factors and the organism has the ability to protect itself from mucus, acidic $\mathrm{PH}$, and peeling [5-6].

H. pylori is the most common infectious human pathogen, infecting more than half of populations worldwide \& is responsible for varieties of upper GI symptoms including dyspepsia, gastritis, and even gastric cancer [7]. Gastric cancer is the fifth most common 
cancer worldwide particularly in Asia [8-9], \& the third most common cause of cancer-related mortality, because the preliminary diagnosis is usually at an advanced stage[10]. H. pylori infection is definitely carcinogenic, and the risk of gastric cancer development for an infected individual is approximately1-2\%[11].

The role of $H$. pylori infection in the pathogenesis of iron deficiency anemia is already validated and more than $60 \%$ of the patients showed complete recovery from anemia after treatment eradication, and those patients who suffering ITP showed normalizing platelet count only after successful $H$. pylori eradication $[12,13]$. The risk of acute coronary artery disease has increased with $\mathrm{H}$. pylori infection, because $\mathrm{H}$. pylori can initiate a persistent chronic inflammatory process inside the gastric epithelium and can also cause systemic inflammatory impacts [14-15].

Stool antigen test (SAT) is more proper than Urea breath test (UBT) for mass analyses. It may provide more accurate results in detecting $\mathrm{H}$. pylori infection when compared with serological tests, that are typically utilized for screening[16]. Both UBT as well as SAT are recommended by guidelines to assess the efficacy of eradication therapy one month after the treatment end[17].

Eradication of H. pylori infection is challenging, and the resistance to antibiotics is the major cause of eradication failure. Regardless of various examinations, the ideal therapeutic regimen has not yet been defined [18]. The clarithromycin-based triple therapy is still suggested in zones with low occurrence of clarithromycin resistance and in patients without history of macrolides experience [19]. Concomitant therapy includes clarithromycinbased triple therapy plus metronidazole $500 \mathrm{mg}$ for 14 days, anyway the frail point in this routine, it loses efficiency in the sight of resistant H. pylori strains to both clarithromycin and metronidazole [20].

A second line treatments including levofloxacinbased triple therapy (PPI 40mg (twice daily ) + levofloxacin $500 \mathrm{mg}$ (once daily) + amoxicillin 1 $\mathrm{g}$ ( twice daily ) for 2 weeks is recommended by guidelines [21]. However, the efficacy of levofloxacin-based second-line therapy seems to be reducing due to growing levofloxacin resistance [22]. Nitazoxanide is (NTZ) is similar to metronidazole, in price, and no recognizable resistance [23], however, it has a potent anti-H pylori effect against metronidazole resistant strains [24]. The aim of this study is to assess the efficacy and tolerability of the standard Clarithromycin-contained triple therapy versus Quadruple regimen therapy in $\mathrm{H}$. pylori infection eradication in Egypt.

\section{SUBJECTS AND METHODS}

\section{Study design}

Our study was cross-section comparative study designated on patients who attending to Gastroenterology clinic in Internal medicine \&Tropical medicine departments, Zagazig University Hospitals during the period from June 2018 to June 2019. Those patients were complaining of recurrent non-specific dyspeptic symptoms and epigastric pain. The study included 140 patients out of 200 patients were examined and found to be positive for stool antigen test for H. pylori infection. We excluded 60 patients before initiation of the study because of their non-compliance and they had recent history of medications for $\mathrm{H}$. pylori eradication. The inclusion criteria composed of patients' ages ranged from 20-60 years old who did not previously receive any treatment regimen for $\mathrm{H}$. pylori infection, no history of ulcer related dyspepsia, or past history of peptic ulcer disease. Meanwhile, the exclusion criteria composed of pregnant or lactating women, history of previous allergic reaction to antibiotics and/or PPIs, any contraindication to treatment drugs, advanced chronic liver disease or renal disease, history of gastro-intestinal bleeding and finally, no history of receiving antibiotics or PPIs within the preceding last month.

All included patients subjected to full clinical examination, full blood count, liver \& kidney function tests, abdominal ultrasound, and proved to be positive for stool antigen test . The study protocol has gained an approval by the institution's board of Medicine, Zagazig University Hospitals, and all participants had assigned a written permission. The treatment regimen was explained in details with benefits and probable side effects before initiation of the study to all participants. Also, phone numbers were taken for follow up. They were distributed into 2 groups. Group (1) composed of 70 patients were given Clarithromycin-contained triple therapy in the form of (Clarithromycin $500 \mathrm{mg}$ twice daily, Amoxicillin 1gm twice daily, Pantoprazole $40 \mathrm{mg}$ twice daily for 2 weeks). 
Group (2) included 70 patients were given Quadruple therapy in the form of (Levofloxacin $500 \mathrm{mg}$ once daily, Nitazoxanide 500mg twice daily, Doxycycline $100 \mathrm{mg}$ twice daily, Pantoprazole $40 \mathrm{mg}$ twice daily for 2 weeks).

During treatment; follow up of the patients to study their compliance to treatment and the probable side effects of the medications, that may include abdominal distension, abdominal pain, unpleasant taste, constipation, dizziness, epigastric pain, lethargy, halitosis, headache, diarrhea, lack of appetite, nausea, vomiting, oral ulcer, \& skin eruption. The response to treatment was evaluated 4 weeks after cessation of therapy. Instructions were given to patients not to receive any antibiotics or PPI for four weeks before retesting there stool for $\mathrm{H}$. pylori antigen.

\section{Method}

Stool antigen test retested for all included patients 4 weeks after cessation of therapy by using rapid test cassette for qualitative detection of $\mathrm{H}$. pylori antigen in human stool samples giving results within 10 minutes. It is a rapid chromatographic immunoassay, in which the membrane is pre-coated with anti-H. pylori antibodies on the test line region during testing the specimen. This blend migrates upward on the membrane by capillary action to react with anti$\mathrm{H}$. pylori antibodies on the membrane and created a colored line. The presence of this colored line in the test region indicates a positive result, while its absence indicates a negative result. To serve as a procedural control, a colored line will always appear in the control line region indicating that proper volume of the specimens has been used and membrane wicking has happened. Invalid result means that the colored line fails to appear. Comparison will be done between both groups to assess the efficacy and tolerability of both regimens.

\section{Statistical analysis}

Data collected throughout history, basic clinical examination, laboratory investigations and outcome measures coded, entered and analyzed using Microsoft Excel software. Data were then imported into statistical package for the social sciences (SPSS version 20.0) software for analysis. According to the type of data, qualitative data represented as number and percentage, \& quantitative data represented by mean \pm SD , the following tests were used to test differences for significance. Differences that are associated of qualitative variable by Chi square $(\chi 2)$ test. Differences between quantitative independent groups by t-test. P-values less than 0.05 were considered as statistically significant. $\mathrm{P}$ value $>0.05$ insignificant, $\mathrm{P}<0.05$ significant, $\mathrm{P}<0.01$ highly significant.

\section{RESULTS}

The study was enrolled 140 patients that were distributed into 2 groups. Our findings showed no significant difference detected between Clarithromycin-contained triple therapy and Quadruple regimen group regarding age, sex and also laboratory investigations (Table 1,2).The side effects for the treatment were 8 cases $(11.4 \%)$ in Quadruple group while 10 cases (14.3\%) in Clarithromycin group (Table 3).The response to treatment (Table 4), the Quadruple group vs. Clarithromycin group was $(85.7 \%$ vs. $67.1 \%$, highly significant $\mathrm{P}<0.01$ ).

Table (1): Distribution of the patients regarding age and sex ( $\mathrm{n}=140)$.

\begin{tabular}{|l|c|c|c|c|}
\hline \multicolumn{1}{|c|}{ parameter } & $\begin{array}{c}\text { Triple therapy } \\
\text { Group (70) }\end{array}$ & $\begin{array}{c}\text { Quadruple therapy } \\
\text { Group (70) }\end{array}$ & t & P value \\
\hline $\begin{array}{c}\text { Age (years) } \\
(\text { Mean } \pm \text { SD ) }\end{array}$ & $43.01 \pm 10.9$ & $44 \pm 13.21$ & 1.85 & $0.06^{*}$ \\
\hline Male \% & $35(50 \%)$ & $30(42.8 \%)$ & & \\
\hline Female \% & $35(50 \%)$ & $40(57.2 \%)$ & & $0.39^{*}$ \\
\hline
\end{tabular}

SD: Standard deviation P: Probability value *: non-significant $(\mathrm{P}>0.05)$ 
Table (2): Laboratory investigations of the studied patients ( $n=140)$.

\begin{tabular}{|c|c|c|c|}
\hline parameter & $\begin{array}{c}\text { Triple therapy } \\
\text { Group (70) } \\
\text { Mean } \pm \text { SD } \\
\end{array}$ & $\begin{array}{c}\text { Quadruple therapy } \\
\text { Group (70) } \\
\text { Mean } \pm \text { SD } \\
\end{array}$ & $P$ value \\
\hline HB (gm/dl) & $12.6 \pm 1.67$ & $12.83 \pm 1.56$ & $0.4 *$ \\
\hline WBCs $\mathrm{mm}^{3}$ & $7.81 \pm 1.21$ & $7.57 \pm 1.87$ & $0.36 *$ \\
\hline Platelet $\mathbf{~ m m}^{3}$ & $234 \pm 60.3$ & $235.8 \pm 69.02$ & $0.87 *$ \\
\hline ALT u/l & $32.1 \pm 5.0$ & $33.2 \pm 3.5$ & $0.13 *$ \\
\hline AST u/l & $36.8 \pm 4.0$ & $36.2 \pm 3.2$ & $0.33 *$ \\
\hline Bl. Urea (mg/dl) & $24.9 \pm 4.4$ & $26.3 \pm 5.5$ & $0.09 *$ \\
\hline S. Cr. (mg/dl) & $0.99 \pm 0.03$ & $0.98 \pm 0.03$ & $0.08 *$ \\
\hline
\end{tabular}

HB : hemoglobin WBCs : white blood cells ALT : alanine aminotransferase

AST : Aspartate aminotransferase Bl. urea : blood urea S. Cr : serum creatinine

$*$ : non-significant $(\mathrm{P}>0.05)$.

Table (3): Side effects of treatment of the two studied groups.(n=140).

\begin{tabular}{|c|c|c|c|c|c|c|}
\hline & & $\begin{array}{c}\text { Triple } \\
\text { therapy } \mathbf{G r} \\
(\mathbf{7 0})\end{array}$ & $\begin{array}{c}\text { Quad. } \\
\text { therapy } \\
\text { Gr(n=70) }\end{array}$ & Total $n=140$ & $\chi^{2}$ & P value \\
\hline \multicolumn{2}{|c|}{ Abdominal pain N (\%) } & $\begin{array}{c}1 \\
1.4 \%\end{array}$ & $\begin{array}{c}1 \\
1.4 \%\end{array}$ & $\begin{array}{c}2 \\
1.4 \%\end{array}$ & \multirow{8}{*}{0.25} & \multirow{8}{*}{$0.61 *$} \\
\hline \multicolumn{2}{|c|}{ Taste disturbance $\mathrm{N}(\%)$} & $\begin{array}{c}2 \\
2.8 \%\end{array}$ & $\begin{array}{c}1 \\
1.4 \%\end{array}$ & $\begin{array}{c}3 \\
2.1 \%\end{array}$ & & \\
\hline \multicolumn{2}{|c|}{ Bloating N(\%) } & $\begin{array}{c}1 \\
1.4 \%\end{array}$ & $\begin{array}{c}2 \\
2.8 \%\end{array}$ & $\begin{array}{c}3 \\
2.1 \%\end{array}$ & & \\
\hline \multicolumn{2}{|c|}{ Diarrhea N(\%) } & $\begin{array}{c}3 \\
4.2 \%\end{array}$ & $\begin{array}{c}1 \\
1.4 \%\end{array}$ & $\begin{array}{c}4 \\
2.8 \%\end{array}$ & & \\
\hline \multicolumn{2}{|c|}{ Nausea $\mathbf{N}(\%)$} & $\begin{array}{c}3 \\
4.2 \% \\
\end{array}$ & $\begin{array}{c}3 \\
4.2 \% \\
\end{array}$ & $\begin{array}{c}6 \\
4.2 \% \\
\end{array}$ & & \\
\hline \multirow[t]{2}{*}{ Total SE } & yes & $10(14.3 \%)$ & $8(11.4 \%)$ & $18(12.9 \%)$ & & \\
\hline & No & $60(85.7 \%)$ & $62(88.6 \%)$ & $122(87.1 \%)$ & & \\
\hline \multicolumn{2}{|c|}{ Total N (\%) } & $\begin{array}{c}70 \\
100 \%\end{array}$ & $\begin{array}{c}70 \\
100 \%\end{array}$ & $\begin{array}{c}140 \\
100 \%\end{array}$ & & \\
\hline
\end{tabular}

SE: side effect $\chi 2$ : Chi square $(\chi 2)$ test $*$ : non-significant $(\mathrm{P}>0.05)$.

Table (4): Response to treatment of $\mathrm{H}$. pylori infection in both regimens.

\begin{tabular}{|l|l|c|c|c|c|c|}
\hline \multicolumn{1}{|c|}{ Parameter } & & Triple & Quadruple & Total & \multirow{2}{*}{$\chi^{2}$} & P value \\
\cline { 1 - 5 } $\begin{array}{l}\text { Negative result } \\
\text { treatment success }\end{array}$ & $\mathrm{N}$ & 47 & 60 & 107 & & \\
\cline { 1 - 6 } $\begin{array}{l}\text { Postive result } \\
\text { (treatment failure ) }\end{array}$ & $\mathrm{N}$ & 23 & $85.7 \%$ & $76.4 \%$ & \multirow{2}{*}{6.7} & \multirow{2}{*}{$0.009 * * *$} \\
\cline { 1 - 5 } Total N (\%) & $\mathrm{N}$ & $32.9 \%$ & $14.3 \%$ & $23.6 \%$ & & \\
\cline { 2 - 6 } & $\%$ & $100 \%$ & $100 \%$ & $100 \%$ & & \\
\hline
\end{tabular}

$\chi 2$ : Chi square $(\chi 2)$ test. $* * *:$ highly significant $(\mathrm{p}<0.01)$ 


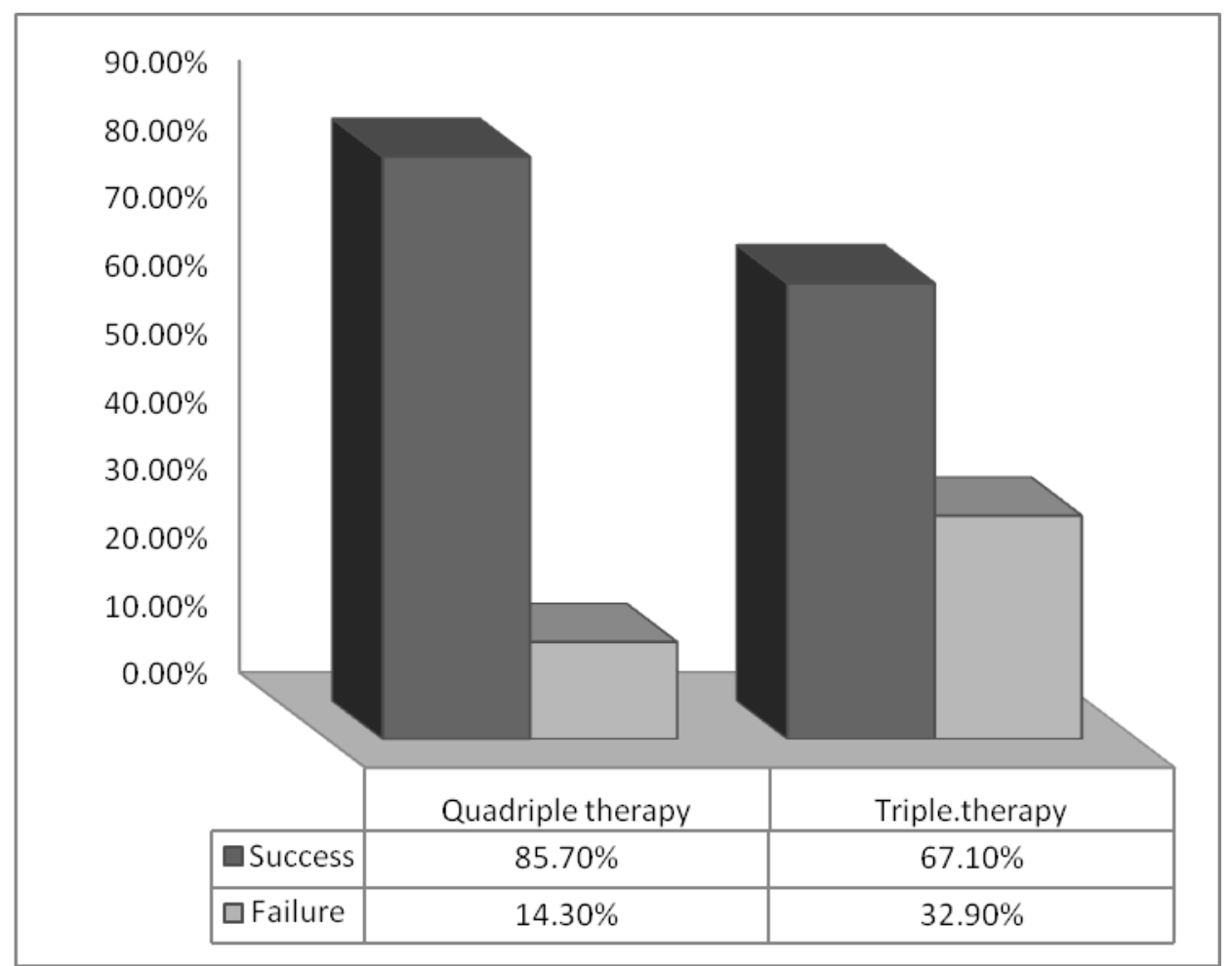

Figure (1): Response to quadruple versus triple based regimen therapy.

\section{DISCUSSION}

H. pylori is a definite carcinogenic pathogen that affects the gastric mucosal layer and the epithelial lining of the stomach, \& build up a prolonged colonization in the stomach mostly during childhood [25,26]. Approximately $90 \%$ of infection remains subclinical and can persist all life if not treated, while $10 \%$ of infected individuals develop obvious clinical disease [27].

The resistant strains and non-compliance of patients are the main causes of treatment failure in obliteration of $\mathrm{H}$. pylori infection $[\mathbf{2 8 , 2 9}]$. The higher prevalence of $\mathrm{H}$. pylori was in developing than in developed countries [25,29]. Egypt is considered one of the highest prevalence areas for $\mathrm{H}$. pylori infection and higher resistance to antibiotics owing to the abuse of antibiotics. The prevalence in Egypt was $90 \%$ in adults while $60-90 \%$ in middle east as reported by the World Gastroenterology Organization (WGO) [30].

Regarding the age and sex, there was no significant statistical differences between two groups clarithromycin - based triple therapy and quadruple therapy $(43.01 \pm 10.9$ vs. $44 \pm 13.21$, $\mathrm{P}=0.06$ respectively) as shown in (Table 1 ). Also, the study showed that relative mild degree of anemia as hemoglobin in both groups triple and quadruple was $(12.6 \pm 1.6$ vs.12.8 \pm
$1.5, \mathrm{P}=0.4$ respectively), however, the statistical analysis was insignificant $(\mathrm{P}>0.05)$.

The overall adverse effects in all enrolled patients were $12.9 \%$. The patients on quadruple regimen therapy exhibited lower adverse effects (11.4\%) compared to patients on clarithromycinbased triple therapy $(14.3 \%)$ however, no statistical significant difference between both group $(11.4 \%$ vs $14.3 \%, \mathrm{P}=0.61)$. The recorded adverse events included taste disturbance, diarrhea, nausea, abdominal pain and distension in tiny percentages. The quadruple regimen therapy showed lower incidence in taste disturbance, abdominal pain, and diarrhea compared to clarithromycin-based triple therapy. There are many studies are consistent with our findings $[\mathbf{3 1}, 32,33]$.

Our study showed the quadruple regimen was generally well-tolerated with mild transient adverse events like taste disturbance, despite four medications included in this regimen. Also, it has been noticed that no patients had discontinued the treatment or was lost to follow up.

Eradication of $\mathrm{H}$. pylori was found to be significantly higher in patients who received quadruple regimen when compared to those who received the standard clarithromycin-based triple 
regimen in $(85.7 \%$ vs. $67.1 \%, \mathrm{P}=0.009)$.These differences indicate that quadruple therapy is more effective than clarithromycin-based triple therapy in eradication of $\mathrm{H}$. pylori infection. Comparable results have been reported in study by Gopal et al. and another study by Cheng $\mathrm{H}$ et al. who compared the standard clarithromycin triple therapy to levofloxacin-contained triple therapy with eradication rates lower than our results $[\mathbf{3 4 , 3 5}]$.

Our results are similar to those obtained by a study of Basu et al. who reported in a randomized study of 270 patients conducted in United States, underwent to quadruple therapy that contained levofloxacin $250 \mathrm{mg}$ once daily, omeprazole $40 \mathrm{mg}$ once daily, nitazoxanide 500 $\mathrm{mg}$ twice daily and doxycycline $100 \mathrm{mg}$ once daily given for 7 or 10 days, produced high eradication rates of $90 \%$ when compared with $73 \%$ with 10 days course of lansoperazole, amoxicillin, and clarithromycin regardless of the duration of therapy [36].

In spite of using higher concentrations of levofloxacin $500 \mathrm{mg}$ once daily, doxycycline $100 \mathrm{mg}$ twice daily, lanzoprazol $40 \mathrm{mg}$ twice daily and the same dose with nitazoxanide $500 \mathrm{mg}$ twice daily and with longer period in treatment (14 days) in our study to ensure adequate eradication, The eradication rate of quadruple-based therapy 7 or 10 days that reported in the study by Basu et al. (90\% vs.73\%) was higher when compared with eradication rate that obtained in our findings $(85.7 \%$ vs. $67.1 \%)$. The decrement in our results may be explained by the reduction in number of included patients and progressing bacterial resistant strains in our locality even with levofloxacin [36]. The higher rates of $\mathrm{H}$. pylori antibiotic resistance in recent years could be explained by the frequent antibiotics usage [37]. A study done in Egypt by Elrazky et al. [38] detected a high incidence of $\mathrm{H}$. pylori resistant strains to clarithromycin (71\%), whereas resistance patterns were less towards levofloxacin $(23.2 \%)$.

In the present study, quadruple-based therapy containing levofloxacin, NTZ and doxycycline surpassed standard clarithromycin-based triple therapy regarding efficacy ( $85.7 \%$ vs. $67.1 \% \mathrm{P}=$ 0.009 ) however, with equal tolerability (mild transient side effects).Regarding relative higher cost of levofloxacin-contained quadruple regimen, this issue may partly affect in the decision to select this regimen and may prevent the use of levofloxacin-contained quadruple regimen as the primary line of empiric treatment for $\mathrm{H}$. pylori eradication. To our knowledge, bismuth-based regimen is not available in Egypt. So, we had to experience another regimen to fulfill the same purpose, improve the eradication rate and produce little side effects.

\section{CONCLUSION}

Quadruple-based therapy is preferable to clarithromycin-contained triple therapy in $\mathrm{H}$. pylori infection eradication particularly in countries like Egypt with great clarithromycin resistance. This is at least until we can get the bismuth in our country. Recently, the increasing concepts about levofloxacin resistance and decreasing efficacy as a second line treatment directed us towards thinking in levofloxacincontained quadruple therapy including doxycycline and NTZ as alternative line of regimen therapy for better $\mathrm{H}$. pylori eradication in our country. Further studies are needed on larger scale of patients, and culture and sensitivity tests are frequently required to evaluate the resistant emergent bacteria. Although culture and sensitivity might not be carried out, the detection of mutations by molecular methods provides an alternative way in which we can relay in the future.

Funding: No funds.

Conflict of interest: The authors declared that there are no conflict of interest.

Ethical approval: The work has been carried out in accordance with The Code of Ethics of the World Medical Association (Declaration of Helsinki) for experiments involving humans. Ethical approval from the ethical committee for Medical Research in the Faculty of Medicine, Zagazig University was obtained prior the study.

A written informed consent was taken from all participants after explaining details and benefits before sharing in the study.

Acknowledgments: We would like to thank John N.K.F. Elmeneawy for helping us in collecting and interviewing our patients \& Justine E. Marcus for doing the statistics and the analysis of data. 


\section{Authors' contributions:}

SAA, NGE \& SSA collected patients' samples and clinical data from outpatient clinic of Internal medicine \& Tropical medicine departments, Zagazig University Hospitals , Zagazig, Egypt and prepared sample for laboratory investigations. All laboratory assessment was supervised by RHE in Medical Microbiology \& Immunology Department , Zagazig University Hospitals, Zagazig, Egypt. Statistical analysis, interpretation of data, and writing the manuscript was done by SAA, and NGE. Critical revision of the manuscript was performed by all of the authors. All authors have read and approved the final manuscript.

\section{REFERENCES}

1. Yamaoka Y. Mechanisms of disease: Helicobacter pylori virulence factors . Nature Reviews Gastroentrology and Hepatology 2010; 7, 29-641. https://doi:10.1038/nrgastro.2010.154

2. Plummer M, Franceschi S, Vignal J, Forman D, De Martel C.Global burden of gastric cancers attributable to Helicobacter pylori. Int $J$ cancer 2015;136(2):487-490.

\section{https://doi.org/10.1002/ijc.28999}

3. Alzahrani S, Lina T , Gonzalez J, Reyes VE. Effect of Helicobacter pylori on gastric epithelial cells .World J Gastroentrol.2014; 20(36) :12 767-80 doi: 10.3748/wjg.

4. Smolka AJ and Backert S. How Helicobacter pylori infection controls gastric acid secretion . $J$ Gastroentrol. 2012; 47: 609-18 DOI 10.1007/s00535-012-0592-1

5. Kalali B, Mejias-Luque R, Java heri A, Gerhard M. H. pylori virulence factors : influence on immune system and pathology. Mediators of inflamm. 2014; 246309 http://dx.doi.org/10.1155/2014/426309

6. Choi YJ. Specific condition : Diagnosis of $\mathrm{H}$. pylori infection in case of upper Gastrointestinal bleeding . Helicobacter pylori 2016; 157-62 DOI 10.1007/978-981-287-706-2

7. Chen C L and Hsu PL. Current advances in the diagnosis and treatment of non-erosive reflux disease . Gastroentrology research \& practice 2013;653989 http://dx.doi.org/10.1155/2013/653989

8. Ferlay J, Soerjomataram I, Dikshit R, Eser S, Mathers C, Rebelo $\mathrm{M}$ et al. Cancer incidence and mortality worldwide : sources, method and major patterns in Globocan 2012.Int,J Cancer 2015; $136 \quad$ (5) : $\quad$ E $359-\mathrm{E} 386$. https://doi.org/10.1002/ijc.29210
9. Herrero R, Park J, Forman D. The fight against gastric cancer-the IARC working group report . Best pract Res clin Gastroentest.2014; 28 (6) : 1107-1114. https://doi.org/10.1016/j.bpg.2014.10.003

10. Hershko $\mathrm{C}$ and Camaschella C. How I treat unexplained refractory iron deficiency anemia . Blood 2014;123 : 326-33. https://doi.org/10.1182/blood-2013-10-512624

11. Frydman GH, Davis N, Beck PL,Fox JG. Helicobacter pylori eradication in patients with immune thrombocytopenic purpura: A review and the role of Biogeography. Helicobacter 2015;20 239-51 https://doi.org/10.1111/hel.12200

12. Lai CY, Yang T, Lin C, Kao CH. Helicobacter pylori infection and the risk of acute coronary syndrome: a nationwide retrospective cohort study. Eur J Clin Microbiol Infect Dis.2015; 34 : 69-74 DOI 10.1007/s10096-014-2207-7

13. Chmiela M, Gajewski A, Rudnicka K. Helicobacter pylori vs coronary heart diseasesearching for connections. world J. Cardiol. 2015 ;7: 187-203. doi: 10.4330/wjc.v7.i4.187

14. Boutari C, Parakakis N, Mantzoro C. Association of Adipokines with development and progression of nonalcoholic fatty liver disease. Endocrinol Metab.(Seoul) 2018; 33 : 33-43 https://doi.org/10.3803/EnM.2018.33.1.33

15. Sumidu Y, Kanemasa k, Imai S, Mori K, Tanaka $\mathrm{S}$, Shimokobe $\mathrm{H}$ et al. Helicobacter pylori infection might have a potential role in hepatocyte ballooning in nonalcoholic fatty liver disease. J Gastroenterol. 2015; 50 : 996-1004 DOI 10.1007/s00535-015-1039-2

16. Choi J, Kim CH, Kim D, Chung SJ, Song JH, Kang JM et al. Prospective evaluation of a new stool antigen test for the detection of Helicobacter pylori, in comparison with histology,rapid urease test,(13) C-urea breath test, and serology .J Gastroenterol Hepatol. 2011;26 1053-1059.

https://doi.org/10.1111/j.1440-746.2011.06705.x

17. Malfertheiner P, Megraud F, O'Morain CA, Atherton J, Axon A, Bazzoli F et al. Management of Helicobacter pylori infection the Maastricht iv / Florence consensus Report .Gut 2012; 61: 646-664. doi:10.1136/gutjnl2012-302084

18. Fock KM, Katelaris P, Sugano K, Ang TL, Hunt R, Talley NJ et al. Second Asia-Pacific consensus Guidelines for Helicobacter pylori infection . J Gastroentrol Hepatol.2009; 24:1587-600. https://doi.org/10.1111/j.14401746.2009.05982.x

19. Chey WD, Leontiadis G, Howden CW, Moss SF. Correction: ACG Clinical

Afifi et al, Afro-Egypt J Infect Endem Dis 2020;10(2):100-107

https://aeji.journals.ekb.eg/

http://mis.zu.edu.eg/ajied/home.aspx 
Guidlines.Treatment of helicobacter pylori infection. Am J Gastroenterol. 2018; Volume 113 - Issue 7 - p 1102. doi: 10.1038/s41395018-0132-6

20. Yucel O. Prevention of Helicobacter pylori infection in childhood. World J Gastroenterol. 2014;10348-54. doi: 10.3748/wjg.v20.i30.10348

21. Georgopoulos SD, Xirouchakis E, MartinezGonzales B, Zampeli E,Grivas E, Spiliad C, et al. Randomized clinical trial comparing ten day concomitant and sequential therapies for Helicobacter pylori eradication in a high clarithromycin resistance area . Eur J Int.Med. 2016;32:84-90.https://doi.org/10.1016/j.ejim. 2016.04.011

22. Yu X, Yang X, Yang T, Dong Q, Wang L, Feng L. Decreasing prevalence of Helicobacter pylori according to birth cohorts in urban China . Turk J Gastroentrol. 2017; 28: 94-97. DOI: 10.5152/tjg.2017.16557

23. Zullo A, De Francesco V, Manes G, Scaccianoce G, Cristofan F,Hassan C. Second-line and rescue therapies for Helicobacter pylori eradication in clinical practice. J Gastrointestin Liver Dis. 2010;192:131-40a85e52f0d65e72776000000.

pdf

24. Guttner Y, Windsor HM, Viiala CH, Dusci L, Marshall BJ. Nitazoxanide in treatment of Helicobacterpylori: a clinical and in vitro study. Antimicrob Agents Chemother. 2003; 47 (12)3780-83.DOI: 10.1128/AAC.47.12.37803783.2003

25. Megraud F, Occhialini A, Rossignol JF. Nitazoxanide, a potential drug for eradication of Helicobacter pylori with no cross-resistance to metronidazole. Antimicro Agents Chemother. 1998;4211:2836-40.

DOI: $10.1128 / A A C .42 .11 .2836$

26. Testerman TL and Morris J. Beyond the stomach : an updated view of Helicobacter pylori pathogenesis, diagnosis, and treatment. World J Gastroentrol. 2014; 20 : 12781-12808. doi: 10.3748/wjg.v20.i36.12781

27. Tanih NF, Okeleye BI, Ndip IM, Clarke AM, Naidoo N, Mkwetshana N, et al. Helicobacter pylori prevalence in dyspeptic patients in the Eastern cape province of South Africa: ethnicity and disease status. South African Med.J. 2010; 100:734-747.

http://dx.doi.org/10.7196/SAMJ.4041

28. Yang J-C, Lu C-W, Lin C-J. Treatment of Helicobacter pylori infection: Current status and future concepts. World J.Gastroentrol. 2014; 20:5283-93. doi: 10.3748/wjg.v20.i18.5283
29. Brown LM. Helicobacter pylori ; epidemiology and routes of transmission. Epidemiol Rev. 2000;22:283-97. 54338a7ec5f86920ecb5a900f63669bb7510.pdf

30. Hunt RH, Xiao SD, Megraud F, Leon-Barua R, Bazzoli F, Merwe SV et al. Helicobacter pylori in developing countries. World Gastroentrology Organization global guidline. J. Gastro-intestin. Liver 2011; Sept. vol;20 No 3;299-304. doi: 10.1097/MCG.0b013e31820fb8f6.

31. Gisbert JP and Morena F. Accuracy of Helicobacter pylori diagnostic tests in patients with bleeding peptic ulcer : a systematic reviews and meta-analysis. Am J Gastroenterol.2006; 101;848-863. PMID: 16494583

32. Chey WD and Wong BC. Practice parameters committee of the American college of Gastroentrology. American college of Gastroentrology guidline on the management of Helicobacter pylori infection. Am.J.Gastroenterol.2007; 102,1808-25. doi: 10.1111/j.1572-0241.2007.01393.x

33. Gisbert JP. Rescue therapy for Helicobacter pylori infection. Gastroenterol Res and pract.2012; 574- 594. doi:10.1155/2012/974594

34. Gopal R, Elamurugan TP, Kate V. Standard triple versus levofloxacin based regimen for eradication of Helicobacter pylori. World J.Gastrointest pharmacol Ther.2013; 4: 23-7. doi: 10.4292/wjgpt.v4.i2.23

35. Cheng H, Hu FL, Zhang GX. Shi RH, Du YQ. Levofloxacin based triple therapy for first line Helicobacter pylori eradication treatment : a multi-control, randomized, controlled clinical study. Zhonghua YI Xue Za Zhi. 2010; 90:79-82. PMID:20356486

36. Basu P, Rayapudi K, Pacana T, Shah NJ. A randomized study comparing levofloxacin, omeprazole, nitazoxanide, and doxycycline vesus triple therapy for the eradication of Helicobacter pylori. Am J Gastroenterol. 2011; 106:1970-1975.

https://www.nature.com/articles/ajg2011306

37. Graham DYand Shiotani A. Which therapy for $H$. pylori infection? Gastroenterology. 2012; 143: 10- 2.DOI: https://doi.org/10.1053/j.gastro. 2012;.05.012

38. Elrazky M, Othman W, Ali MA, Shehta A. Fluoroquinolone-resistant Helicobacter pylori strains isolated from one Egyptian University Hospital: molecular aspects. J Microbiol Antimicrob Agents 2016; 2:26-31. ISSN 2396880X. 